\title{
بناء هقياس الرضا عن الدور القيادي لرؤساء الفرق لبعض الألعاب الفرقية في العراق
}

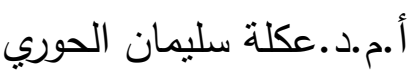

م.م.سعدون عبد الرضا فرحان

جامعة ديالى / كلية التربية الرياضية الرضان فرحان

إن البحوث والدراسات النفسية الحديثة لكثير من الاحتفالات الرياضية وعدم الحصول على نتائج

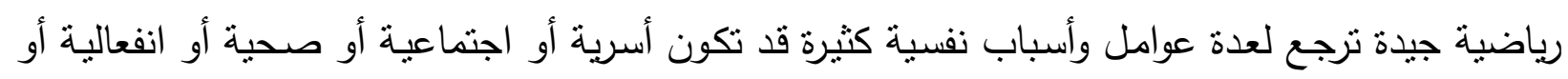

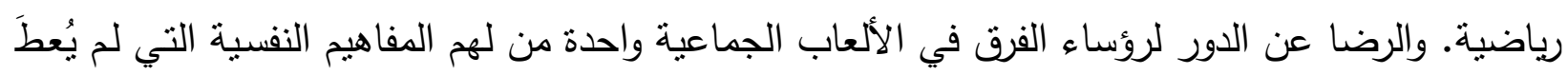

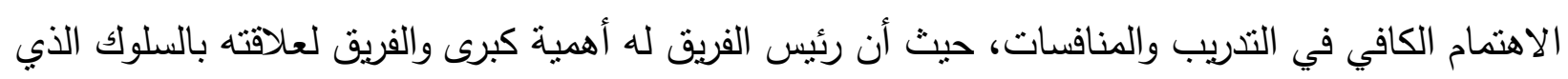

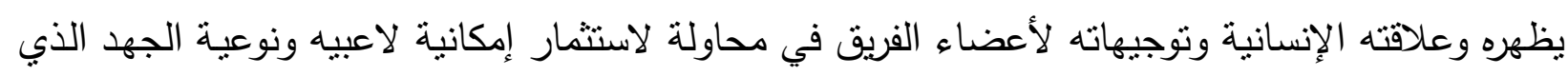

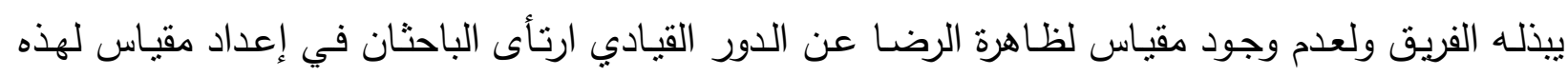

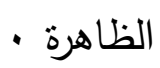

\section{هشكلة البحث}

تتمثل مشكلة البحث بعدم وجود أداة لقياس الرضا عن الدور القيادي لرؤساء الفرق في الألعاب

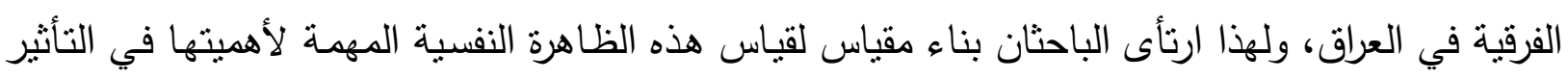
على بقية أعضاء الفريق.

إعداد وبناء مقياس للرضا عن الدور القيادي لرؤساء الفرق لبعض الألعاب الفرقية في العراق.

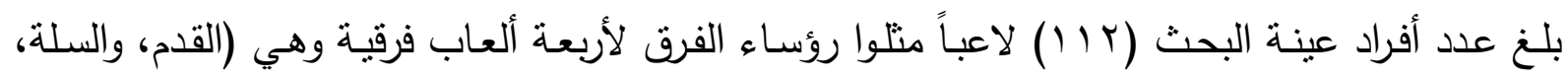
والطائرة، واليد).

\section{أهم الاستنتاجات}

•. التوصل إلى بناء أداة قياس الرضا القيادي لرؤساء الفرق في الألعاب الفرقية في العراق.

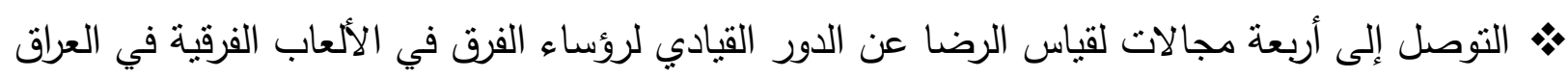

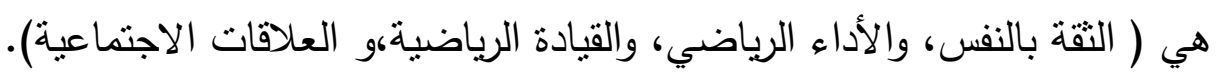

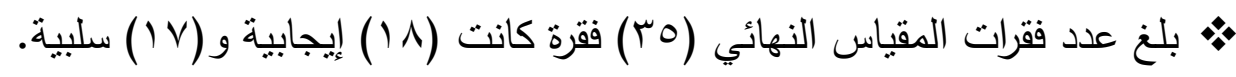

• إمكانية استخدام الددربين لدقياس الرضا عن الدور القيادي لرؤساء الفرق للنأكد من أن ضغوط التدريب والمنافسات لم تؤثر سلباً في نفس رئيس الفريق. 
• استخدام المقياس الحالي للكثف عن علاقة الرضا عن الدور بالمتغيرات النفسية الأخرى أو بنتائج الفريق. •• استخدام المقياس الحالي للمقارنة بين الرضا عن الدور لرؤساء الفرق بين ألعاب(كرة القدم، والسلة، والطائرة، واليد ).

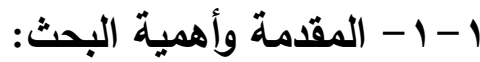

إن الإنجازات الرياضية العالية المتحققة من قبل الرياضيين في الألعاب الرياضية المختلفة بشكل

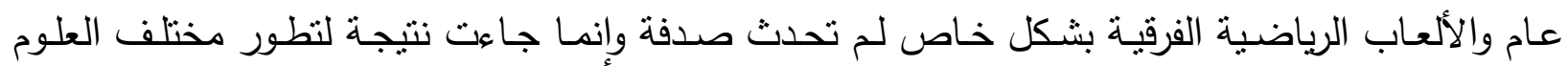
الرياضية وما يخص الإعداد النفسي واتباع المدربين المناهج العلمية الصحيحة في محاولة لاستثمار الطاقة

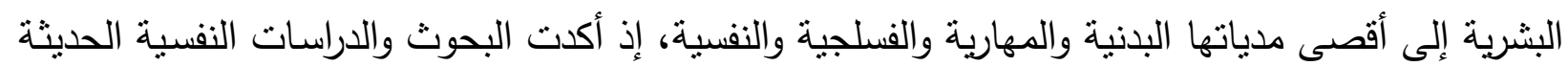
لكثير من الإخفاقات الرياضية، وعدم الحصول على نتائج رياضية جيدة نرجع إلى عوامل وأسباب نفسية ولئه

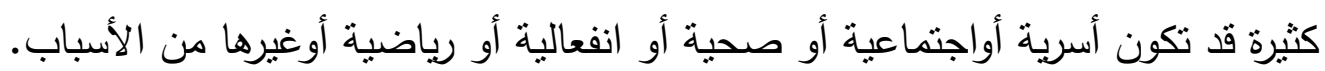

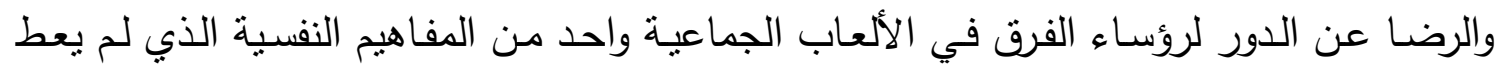
الاهتمام الكافي، في التنريب والمنافسات في بلدنا على الرغم من دوره المهم والفاعل في التقليل من حدوث التأثثرات السلبية على تماسك أعضاء الفريق الواحد خلال فترتي التدريب والمنافسات.

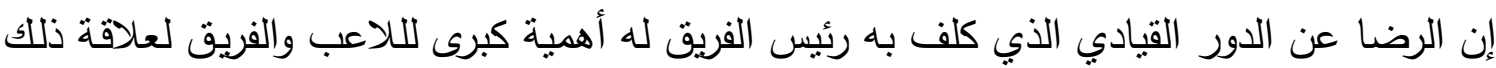

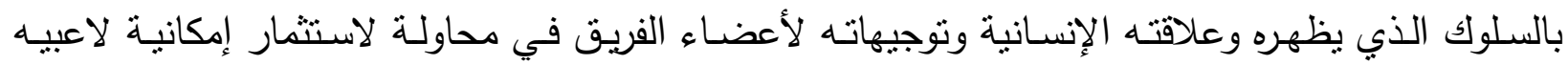
ونوعية الجهد الذي يبذله الفريق، الأمر الذي يؤدي إلى تحسين العملية النتريبية وتطوير مستوى الإنجاز الرياضي. من خلال ما تقدم يرى الباحثان أن أهمية الدراسة تكمن في أن الرضـا عن الدور القيادي مهم وأساس

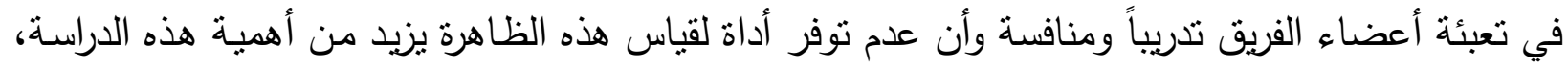

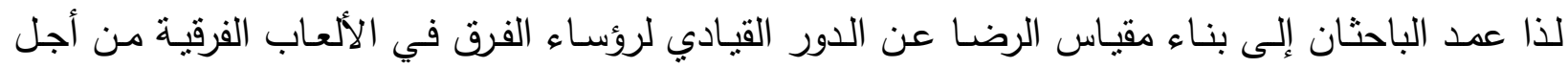
مساعدة المدربين واللاعبين لاكتثاف هذه الظاهرة السلوكية المهمة والوقوف على مدياتها.

تمثل ظاهرة الرضا عن الدور القيادي إحدى الظواهر النفسية المهمة في المجال الرياضي كونها

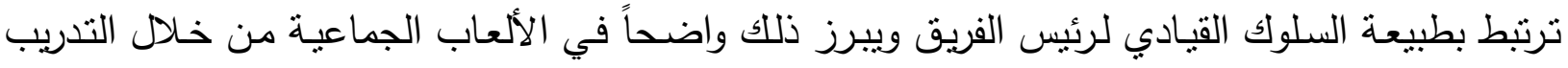

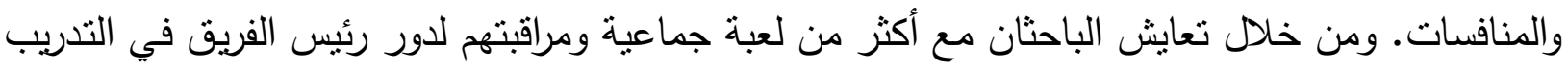
والمنافسات وجدوا أن هذه الظاهرة لم تعط الاهتمام الذي تستحقه على الرغم من علاقتهاتها بقائد الفريق ودوره القيادي للفريق ودليلنا على ذلك عدم وجود أداة قياس الرضـا عن الدور القيادي لرؤسـاء الفرق للاعبين 
المتقدمين للألعاب الفرقية في العراق لهذا ارتأى الباحثان أن يقوما بإعداد وبناء مقياس يتلاءم مع واقع البيئة العراقية لقياس هذه الظاهرة وتتخيصها بدقة.

ו-r- هدف البمث:

إعداد وبناء مقياس الرضا عن الدور القيادي لرؤساء الفرق لبعض الألعاب الفرقية في العراق.

1-\$- هجالات البحث:

1- - - - - المجال البشري: رؤساء الفرق الرياضية لألعاب كرة القدم والسلة والطائرة واليد لأندية المتقدمين

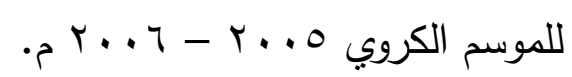

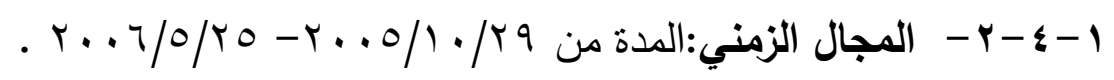

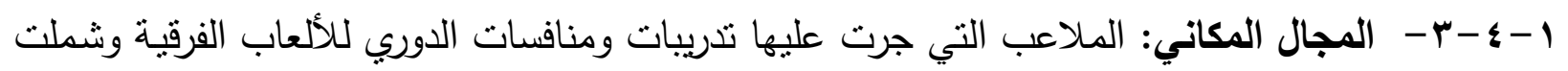
أغلب محافظات العراق.

1-0- تصديد المطالحات

أ. الرضا عن الدور: "هو محصلة عدد من المشاعر المتعلقة بالدور، وهذا المتغير تتدرج فيه المشاعر تجاه

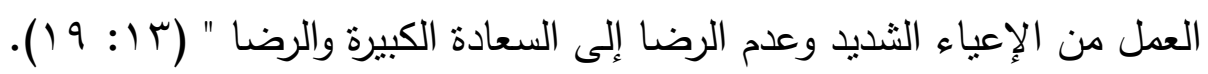

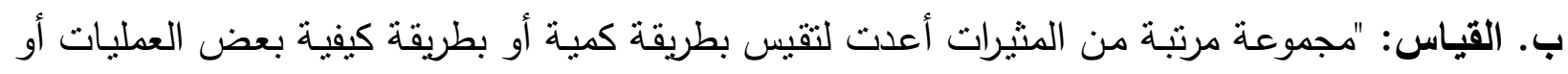

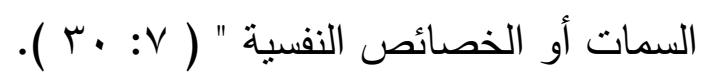

\section{r - ب الدراسات النظلرية}

ץ- - - مفهوم الرضا عن الدور: يمثل الرضا عن الدور دالة الإنسان واستقراره في عمله وما يحقق لهذا

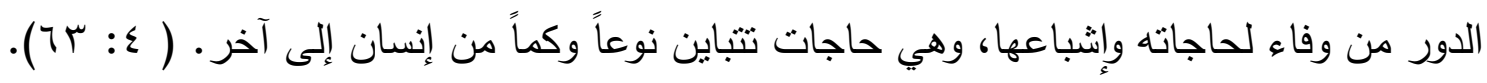

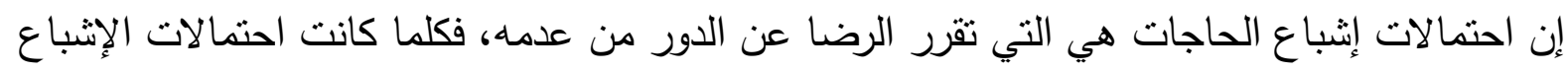

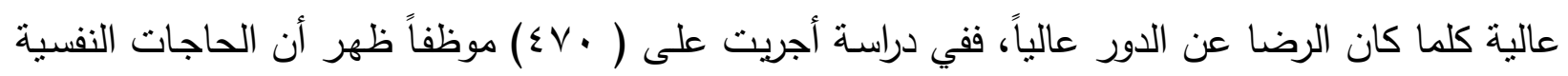

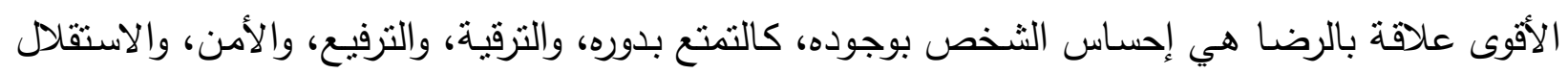

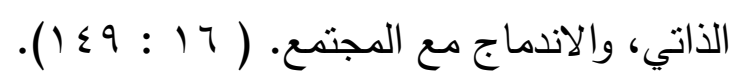

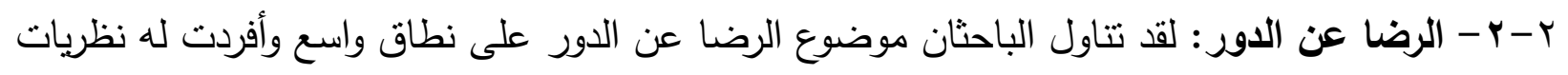

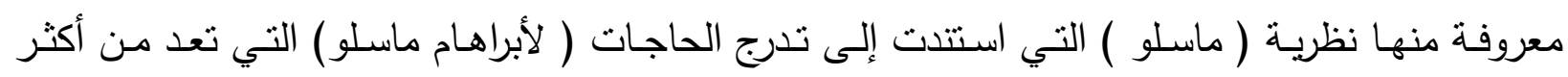

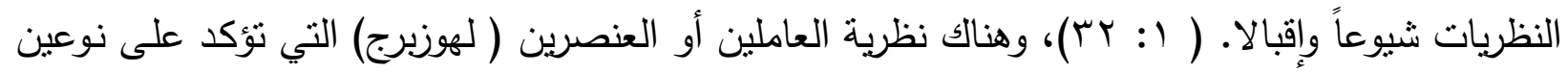

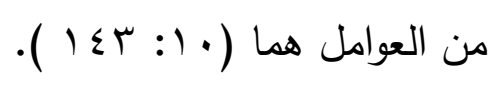

1- العوامل الداخلية التي تكون مرادفة للعوامل الدافعة. r- العوامل الخارجية الني تكون مرادفة للعوامل الصحية.

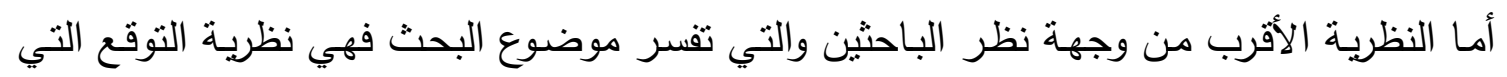

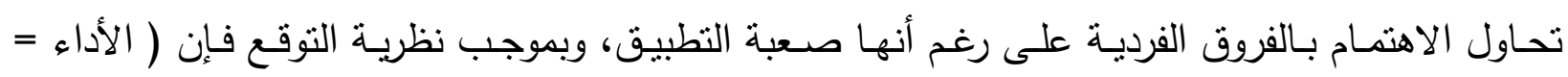


التحفيز × القابلية ) أي أن مستوى الأداء ( وجود أداء فرد ما، لعمل ما ) هي دالة العاملين هما التحفيز

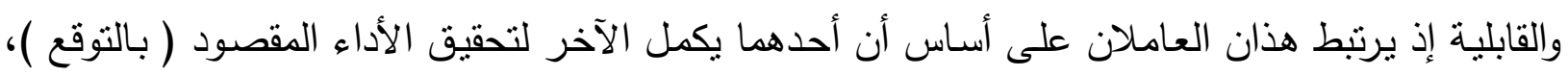

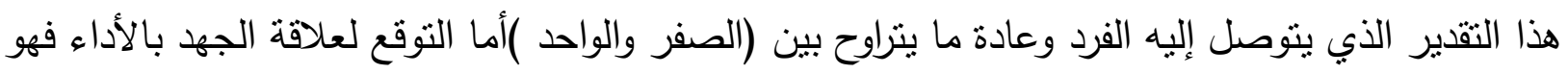

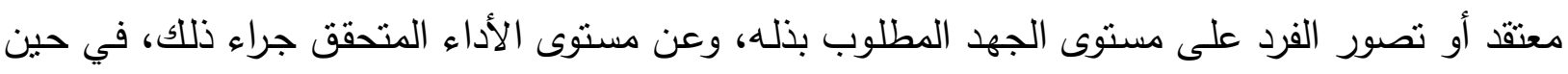
أن توقع علاقة الأداء بالنتيجة هو تصور الفرد عن العلاقة بين مستوى معين من الأداء وبين تحقيق النتيجة

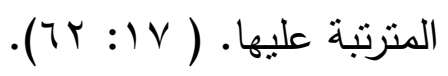

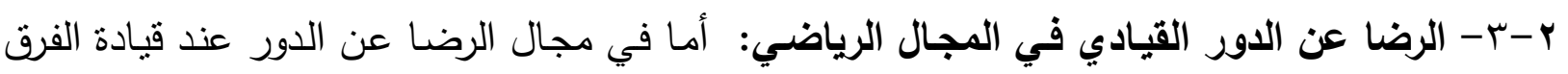

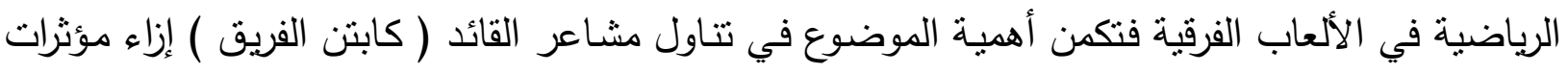

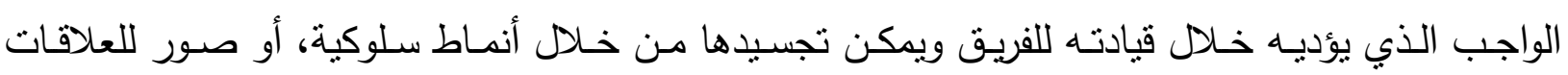

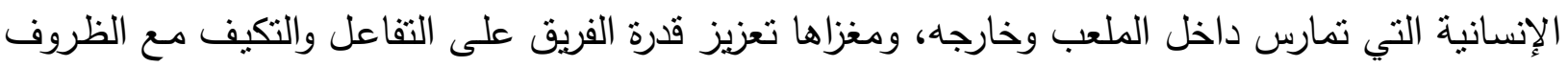
خلال وقت المنافسات وفي أوقات التحضير لها وبعدها.

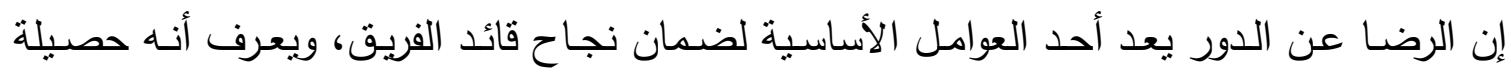

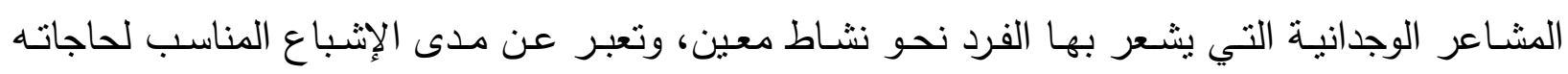

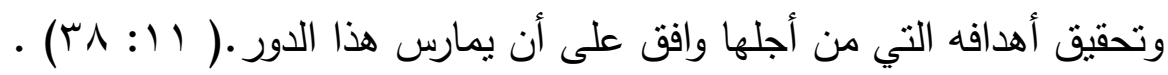

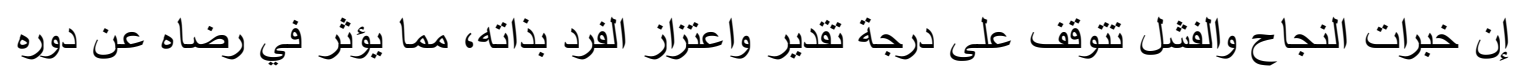

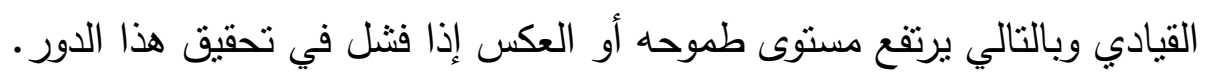

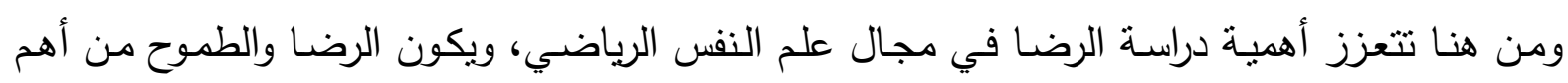

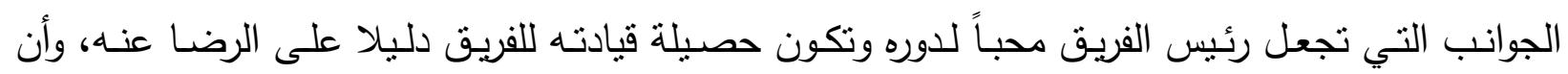

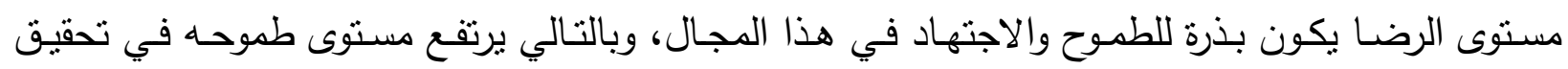
أهدافه، فقائد الفريق يشعر بالرضا حين يتحقق مستوى طموحه، والعكس إذا فثل في تحقيق هذا المستوى. ( (1) $1: 10$

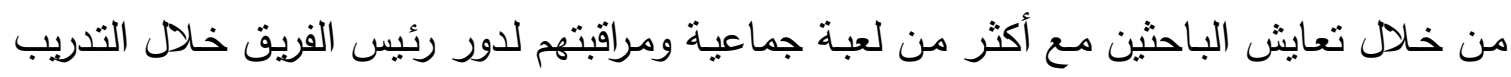
والمنافسة وجدوا أن هذه الظاهرة لم تعط الاهتمام الذي تستحقه على الرغم من علاقتها بقائد الفريق ودوره

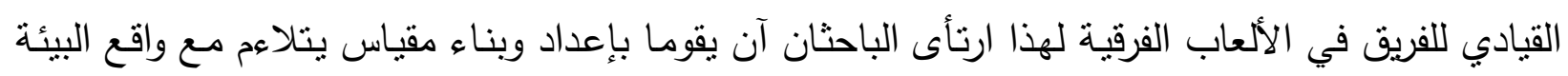

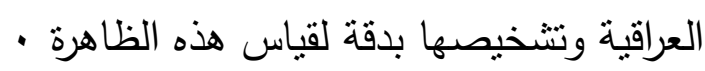

r- - منهج البحث: استخدم الباحثان المنهج الوصفي بطريقة الاسلوب السسحي لأنه الاسلوب الأكثر ملاعمة لطبيعة المشكلة وتحقيق هذه الدراسة.

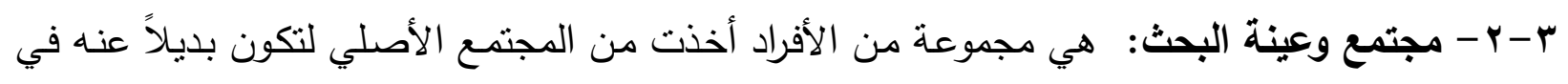

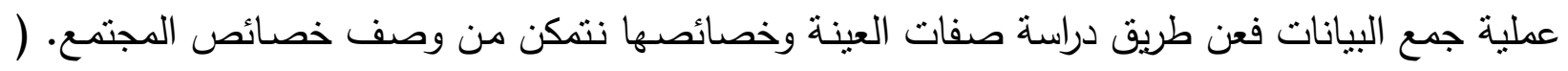




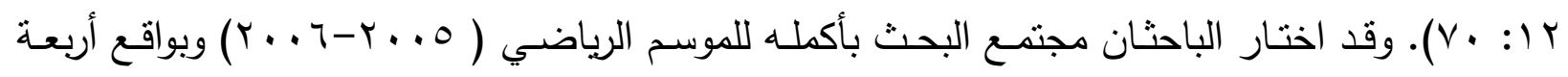

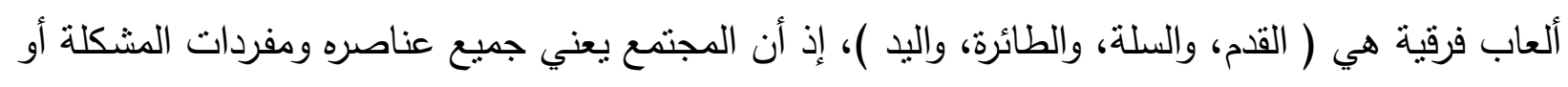

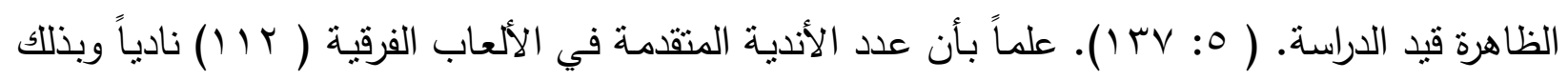

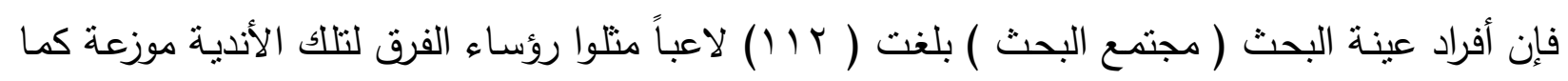
يأني:

جدول رقم ( )

\begin{tabular}{|c|c|c|c|c|c|}
\hline \multirow{2}{*}{ المجموع } & عينة التحليل الإحصائي للفرق & عينة & المستتعدون & & المتغيرات \\
\hline & الخاصة بأداء البحث & 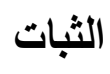 & & الاستطلاعية & التلاعبون \\
\hline $11 r$ & $\wedge \wedge$ & 1. & 7 & $\wedge$ & اللاعبين \\
\hline
\end{tabular}

r-r- الوسائل والأجهزة والأدوات المستخدم:الدصادر العربية والأجنبية

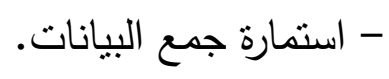

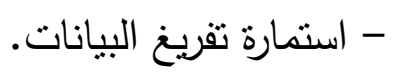

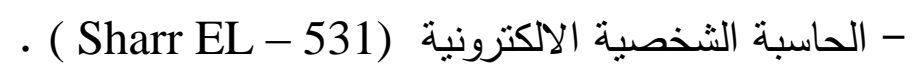
- شبكة المعلومات الدولية . (Internet).

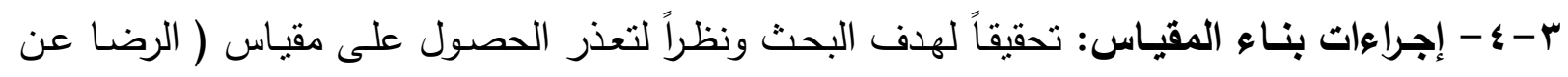

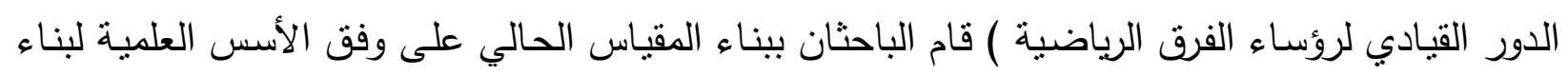
المقاييس وذلك من خلال ما يأتي:

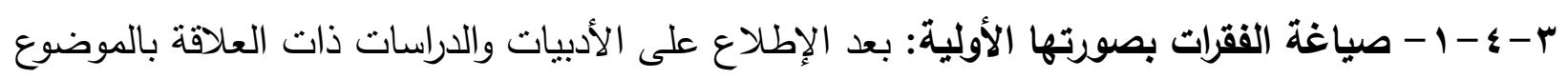

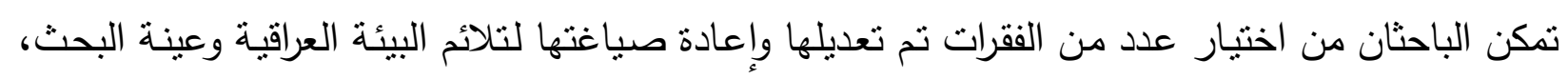

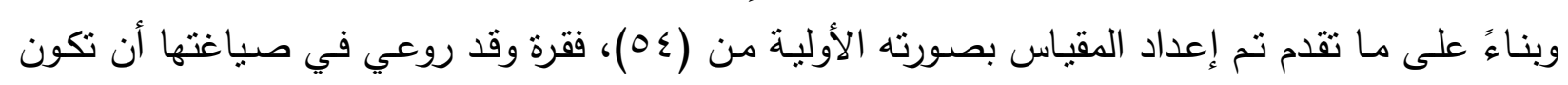

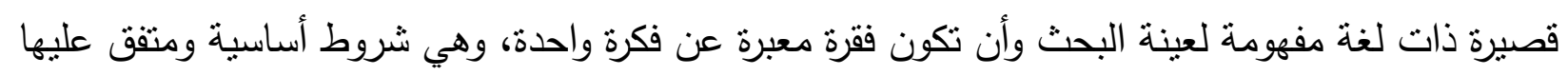

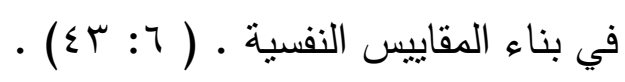
rr-צ-r-1 - - - صدق المحكمين ( Seale Validity) : بعد إعداد فقرات المقياس وصياغتها بصورتها

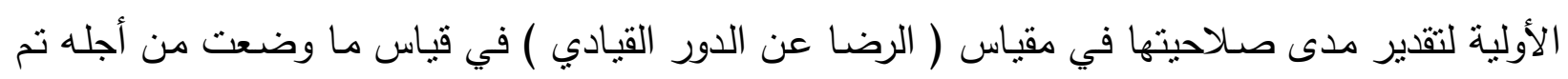

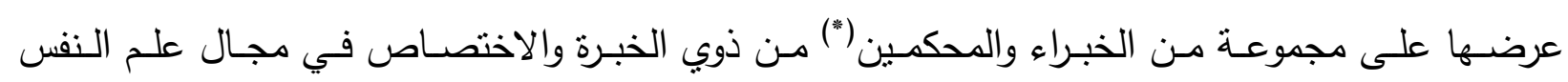


الرياضي والقياس والتقويم والألعاب الفرقية لغرض إبداء رأيهم في كل فقرة من حيث صلاحيتها وكونها تعبر

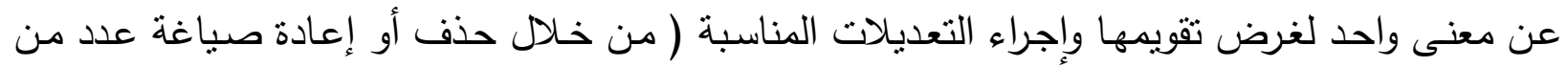
الفقرات ) مع ذكر المحور الذي تمثله ضمن القياس، والبدائل المقترحة للإجابة واستقرار رأي (

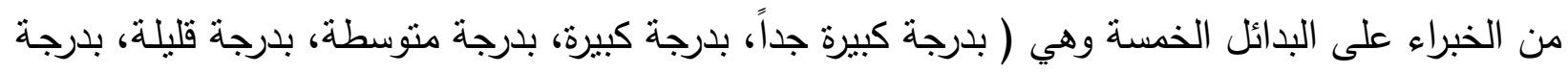

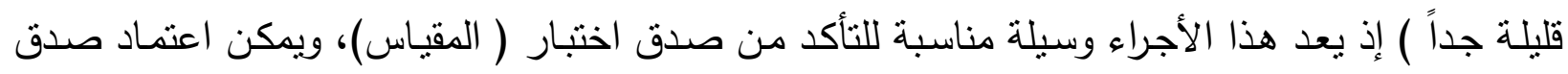

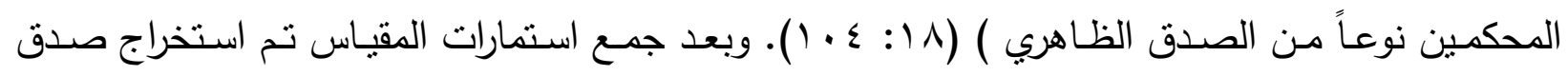

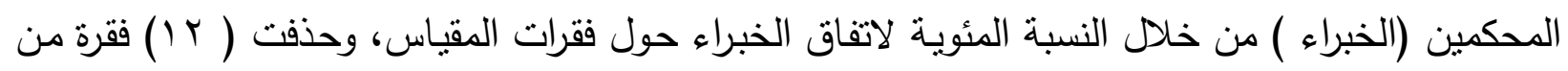

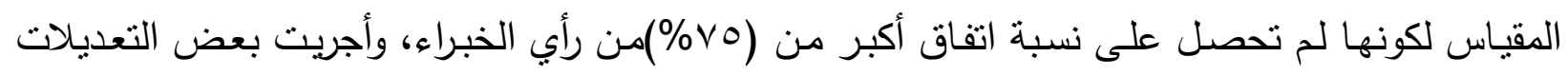

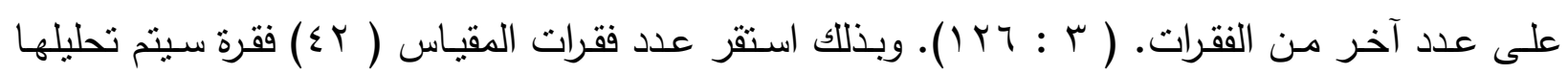

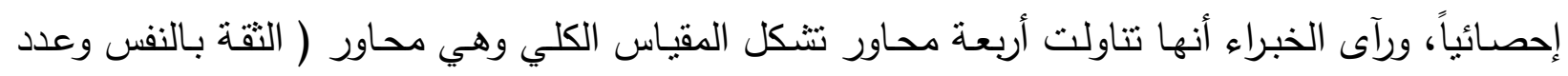

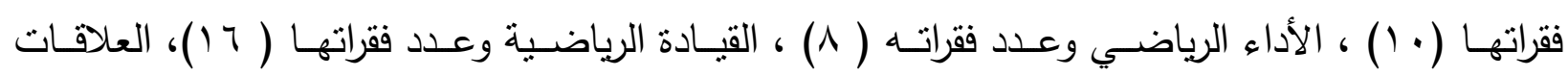
الاجتماعية وعدد فقراتها (^).

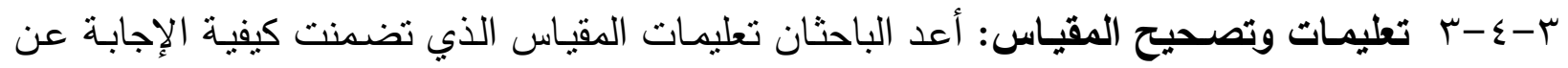

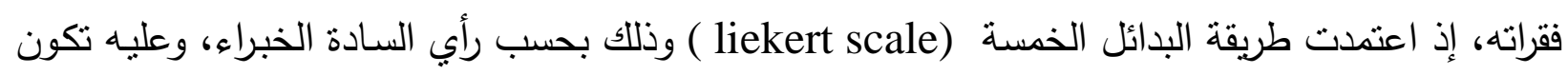

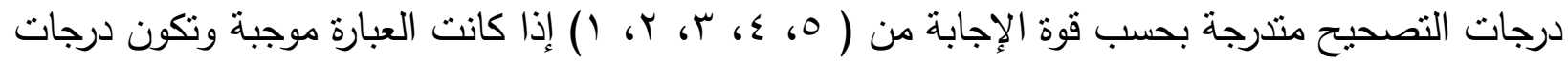

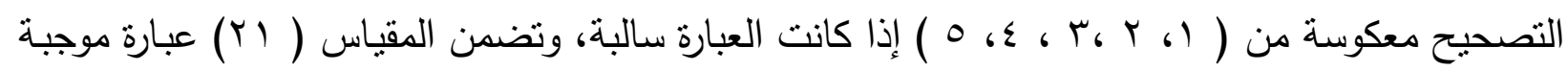

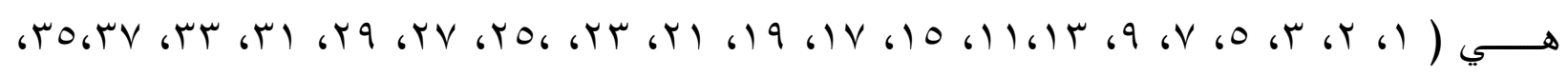
V .

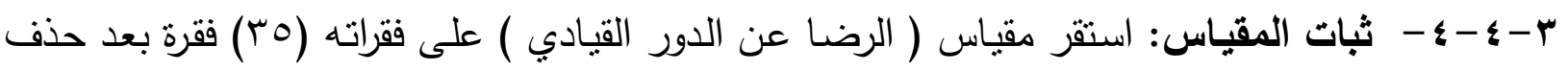

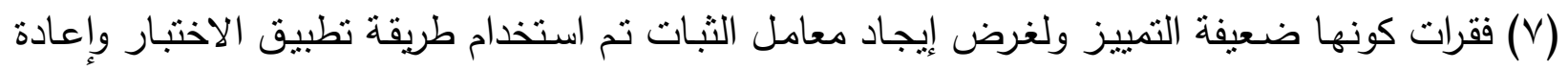

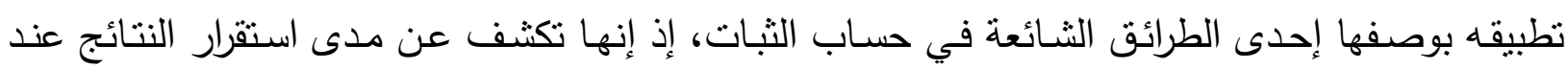

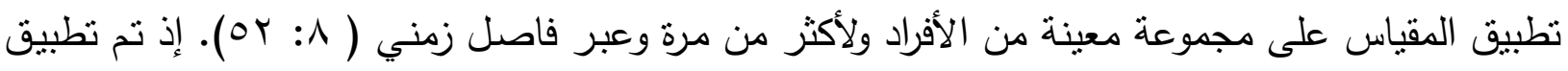

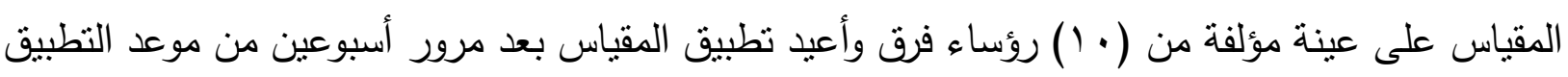

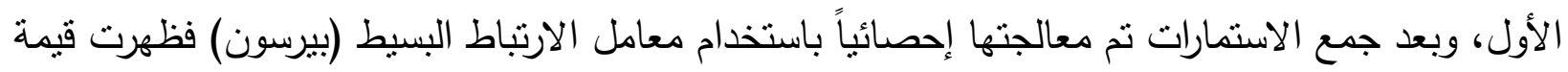

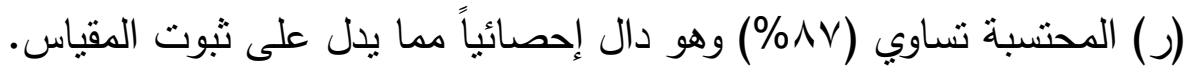


ب-0- التجريـة الاسـتطلاعية: تعد التجربـة الاستطلاعية تدريباً علمياً للبـاحثين للوقوف على السلبيات

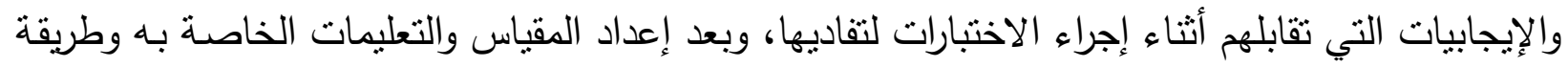
التصحيح نم تطبيقه على عينة قوامها ( ^) لاعبين من كل لعبة من لعب ( القدم، والسلة، والطائرة، واليد) اختيروا بطريقة عشوائية وكان الغرض من التجربة ما يأتي: فئي - التأكد من وضوح تعليمات المقياس - التعرف على ملاعمة فقرات المقياس المعدة لهذا الغرض.

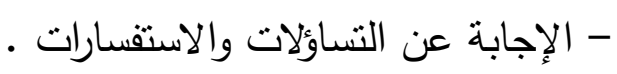

- تشخيص الصورة النهائية للفقرات قبل تطبيقها النهائي وتحليلها إحصائياً.

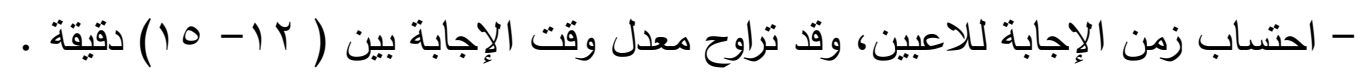

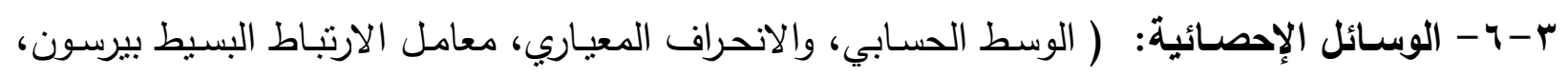

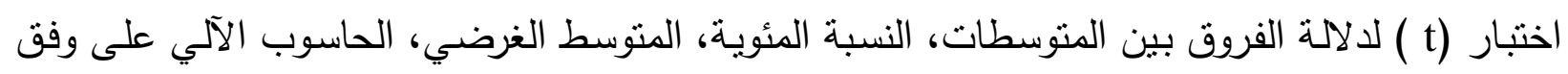
نظام (Spss) لتحليل البيانات في البحث الحالي.

\section{ع -عرض النتائج وتمليلها ومناقشتهـا:}

؛ - 1 - عرض نتائج فقرات المقياس وتحليلها ومناقشتها: يوضح الجدول (1) الوصف الإحصائي للفرق

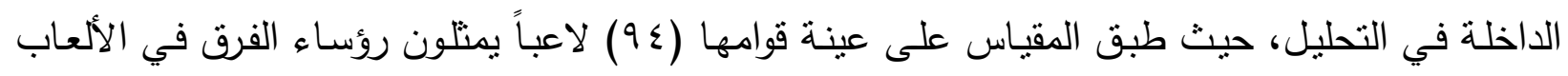

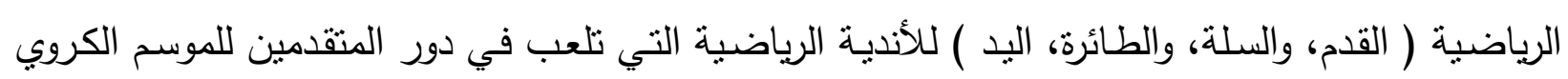

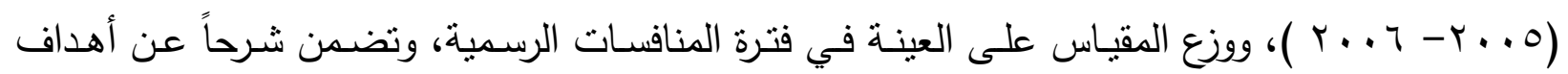

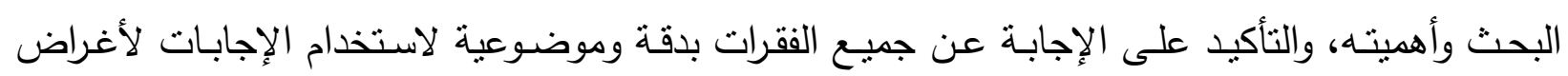

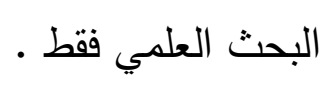
צ - 1 - 1 - معامل الاتساق الداخلي (Internal Consistency Coefficient): تم استخراج معامل

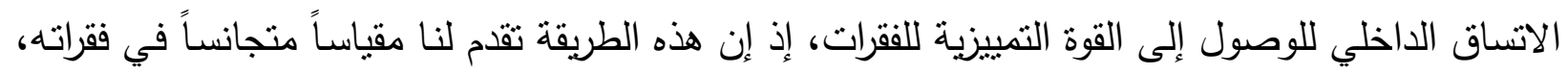
حيث تقيس كل فقرة البعد السلوكي الذي يقيسه المقياس كله فضلاً عن قدرتها على أبراز الترابط بين الفقرات

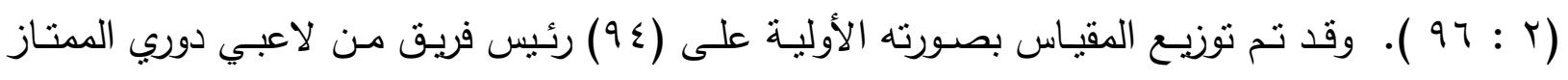

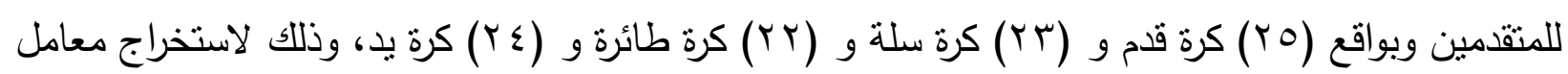
الاتساق الداخلي بين فقرات المقياس والدرجة الكلية للمقياس باستخدام معامل الارتباط البسيط (بيرسون)على (باتى وفق نظام (Spss) على الحاسب الآلي، كما مبين في الجدول (r) . 


\section{الجدول رقم (r r)}

يبين معامل الارتباط بين فقرات المقياس ( الرضا عن الدور القيادي) والدرجة الكلية للمقياس باستخدام طريقة الاتساق الداخلي

\begin{tabular}{|c|c|c|c|c|c|c|c|}
\hline معامل تمييز & الفقرة & معامل تمييز & رقم & معامل تمييز & رقم & معامل تمييز & رقم \\
\hline • r rVT & Tร & $\cdot, r \wedge r$ & rr & $\cdot, \leq \leqslant 0$ & Ir & $\cdot, \leqslant \vee q$ & 1 \\
\hline$\cdot r \leqslant 0$ & ro & •, Y\A & Y $\varepsilon$ & • & T & $\cdot, r \leq T$ & r \\
\hline r & qu & $\cdot, \leq \leq \leq$ & ro & $\cdot, r \neg \Lambda$ & $1 \varepsilon$ & גדז, & r \\
\hline$\cdot, Y \backslash V$ & rV & ו ו, , & rq & $\cdot r \leqslant 0$ & 10 & , & $\varepsilon$ \\
\hline$(*) \cdot, 191$ & एᄉ & $\cdot, \leqslant \backslash \wedge$ & TV & $(*) \cdot, r \cdot Y$ & 17 & - & 0 \\
\hline$\cdot, M V I$ & rq & - Y Y & rᄉ & זrY, . & $1 V$ & $\cdot, Y \backslash V$ & 7 \\
\hline$\cdot, \varepsilon \cdot \Lambda$ & $\varepsilon$. & $\cdot, \varepsilon \wedge \varepsilon$ & $r q$ & $\cdot, Y 01$ & 11 & $\cdot r \wedge r$ & V \\
\hline$\cdot, Y \neg \Lambda$ & $\varepsilon 1$ & $\cdot, r q \leq$ & r. & $\cdot, r \leq V$ & 19 & -,$Y q \leq$ & $\wedge$ \\
\hline$\cdot, r \leqslant V$ & $\varepsilon r$ & $\cdot, r \neg \Lambda$ & ו & • & $r$. & $\cdot, r \wedge$. & 9 \\
\hline- & $\varepsilon$ & ו & r & $\left({ }^{*}\right) \cdot, r \cdot \varepsilon$ & YI & $(*),, 1 \wedge 9$ & 1 . \\
\hline- & $\varepsilon \varepsilon$ & • & سז & $\cdot, Y V Y$ & Yr & ו & 11 \\
\hline
\end{tabular}

يتضح في الجدول (r) إن قيم معامل الارتباط بين فقرات المقياس والدرجة الكلية للمقياس قد تراوحت بين

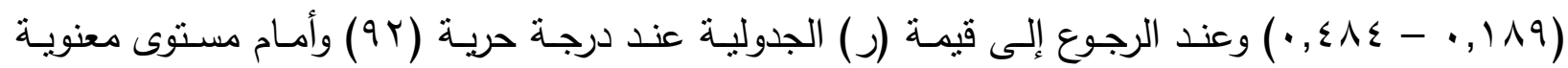

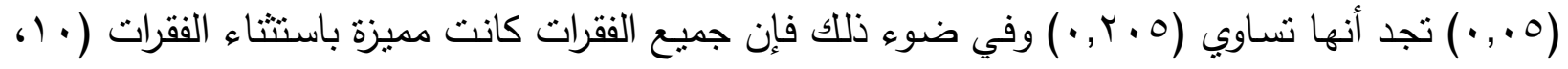
ج (، ا⿰忄، ^ץ) فهي فقرات ضعيفة التمييز وقد تم حذفها وذلك لأن قيم معامل الارتباط الخاصة بها كانت أقل من قيمة (ر) الجدولية.(ع ا: هباء ) ) ع - ا - - اسلوب المجموعات المتطرفة (Contrasted Groups) : تم استخدام اسلوب الجماعات المتطرفة للكثف عن الفقرات المميزة في بناء مقياس (الرضا عن الدور القيادي )، ويتضمن هذا الأسلوب تقسيم العينة إلى مجموعتين متطرفتين، ولتحقيق ذللك رتبنا درجات رؤساء الفرق ترتيبا تتازلياً من الأعلى إلى الأدنى، ثم قسمناها إلى مجموعتين متسـاويتين، ثم حددت المجموعتان المتطرفتان بالدرجة بنسبة (r.

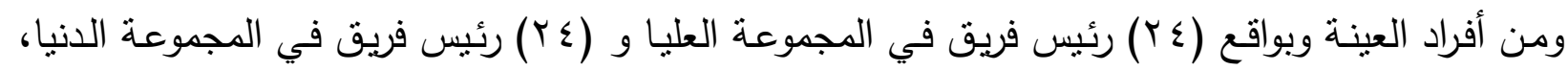
ولغرض حسـاب معامل تمبيز كل فقرة من فقرات المقياس استخدم الباحثان نظام (SpSS) في الحاسوب الآلي، واعتمدت القيمة التائية إحصائيا مؤشراً لتمبيز الفقرات، والجدول (r) يبين تفاصيل ذلك . (ب) (الجدول (r) 
يبين قيمة (ت) الدحسوبة لفقرات مقياس (الرضا عن الدور القيادي) باستخدام اسلوب المجموعات المنطرفة

\begin{tabular}{|c|c|c|c|c|c|c|c|}
\hline قليمة (ت) & قم الفقرة & قالمحسة (ت) & رقم الفقرة & قالمحسة (ت) & رقم الفقرة & قالمحسوبة (ت) & رقم \\
\hline$r, O V$ & $r \varepsilon$ & (*) 1,97 & r & $T, Y \varepsilon$ & Ir & $r, I r$ & 1 \\
\hline$r, 7)$ & ro & $r, \varepsilon r$ & $r \varepsilon$ & $\varepsilon, T V$ & $1 \pi$ & $r, 7)$ & r \\
\hline r,VA & Tr & $r, r q$ & ro & $\varepsilon, 1 \leqslant$ & $1 \leq$ & $r, r \leqslant$ & $r$ \\
\hline Y,OV & rV & $r, I r$ & r & $r, 17$ & 10 & (*) $1,1 \wedge \varepsilon$ & $\varepsilon$ \\
\hline (*) 1,9 & $\mu_{\Lambda}$ & $r, 00$ & TV & ד, & 17 & $\varepsilon, .1$ & 0 \\
\hline$r, \cdot V$ & rq & $r, 99$ & rA & $r, 7)$ & IV & $r, \wedge r$ & 7 \\
\hline$Y, Y \varepsilon$ & $\varepsilon$. & $r, 7)$ & rq & $\left(^{*}\right) 1, \vee 9$ & 11 & $r, Y \wedge$ & v \\
\hline$r, 17$ & \&1 & $\varepsilon, \Gamma\urcorner$ & r. & $r, \cdot \Lambda$ & 19 & $r, Y q$ & $\wedge$ \\
\hline$\varepsilon, .1$ & $\varepsilon r$ & Y,OV & I & $r, \cdot V$ & $r$. & $r, 00$ & 9 \\
\hline- & $\varepsilon r$ & T, ז & Tr & $r, \vee \wedge$ & rI & $\left(^{*}\right) \quad, \wedge \Lambda$ & 1. \\
\hline - & $\varepsilon \varepsilon$ & $r, I r$ & Tr & $r, \varepsilon r$ & Yr & $r, q q$ & 11 \\
\hline
\end{tabular}

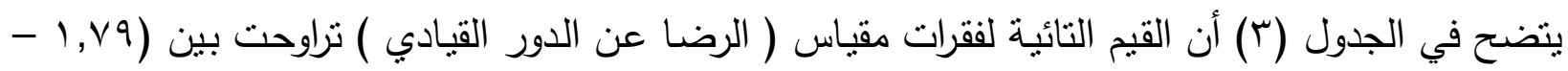

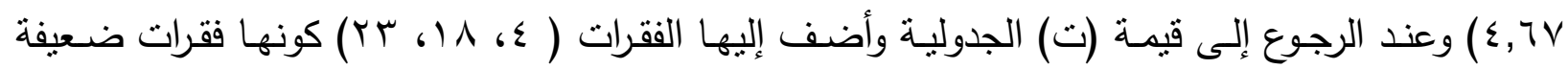

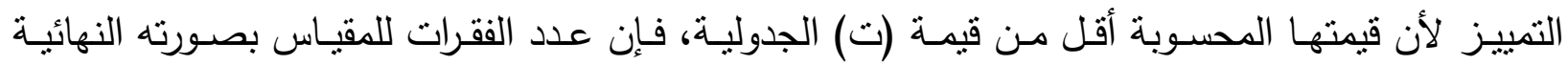

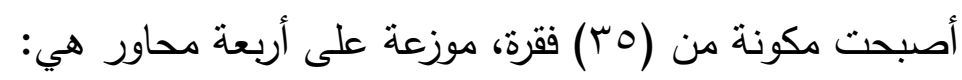

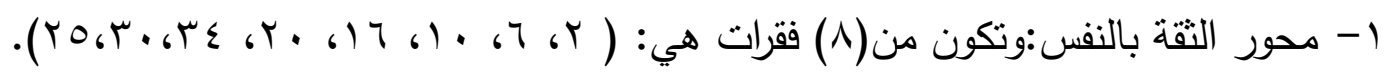

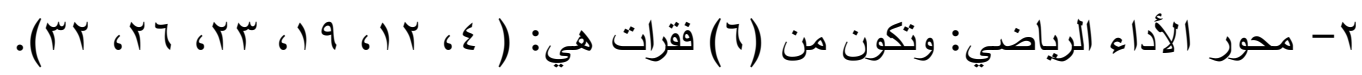

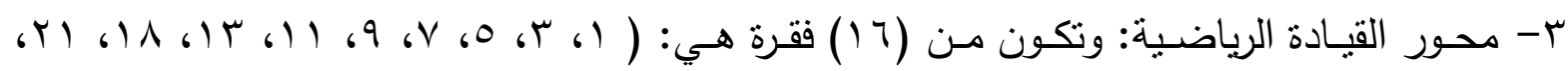

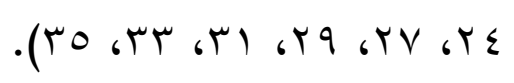

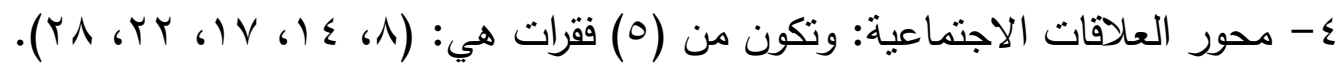

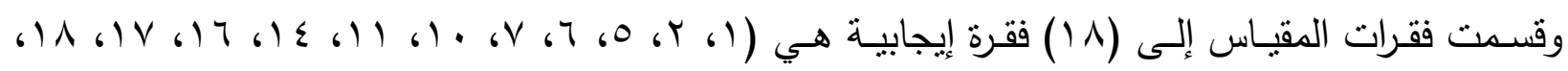
(Y)

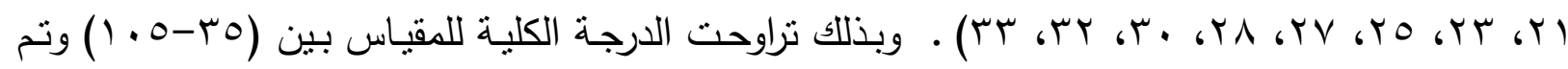

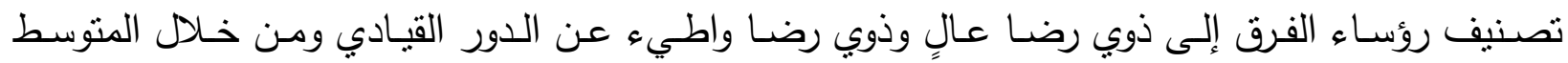

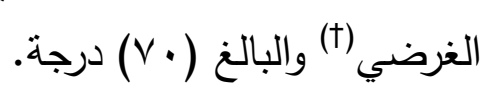

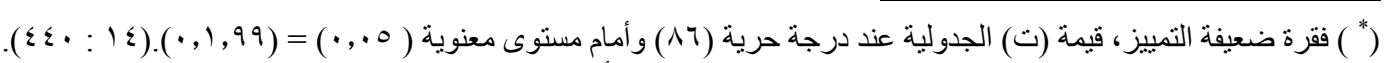
مجموع درجات البدائل لأعداد الفقرات 


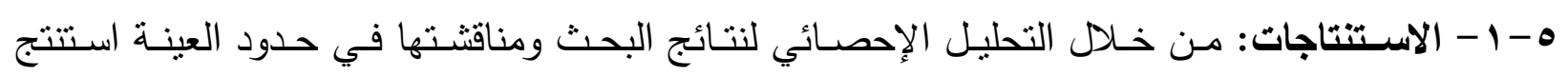

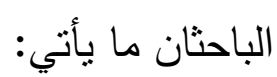
1-توصل الباحثن إلى بناء أداة قياس الرضا عن الدور القيادي لرؤساء الفرق في الألعاب الفرقية في العراق.

r- في ضوء النتائج التي أقرها المحكمون والتحليل الإحصائي تم التوصل إلى أربعة مجالات لقياس

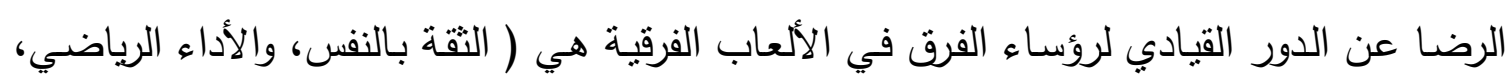
والقيادة الرياضية، والعلاقات الاجتماعية ).

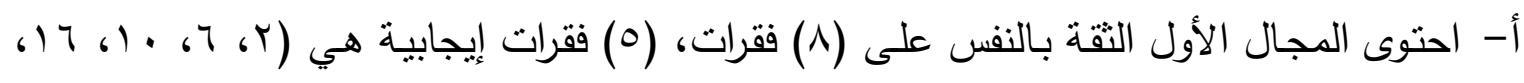

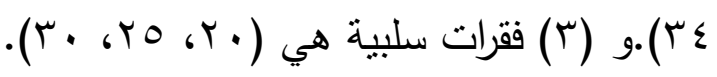

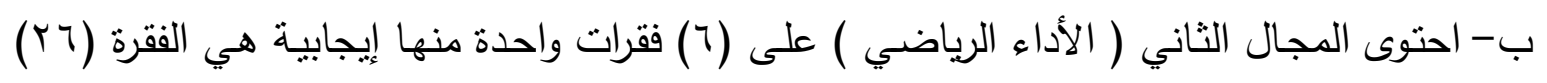

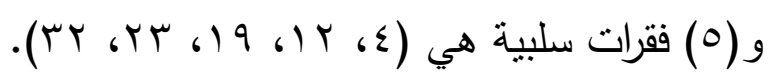

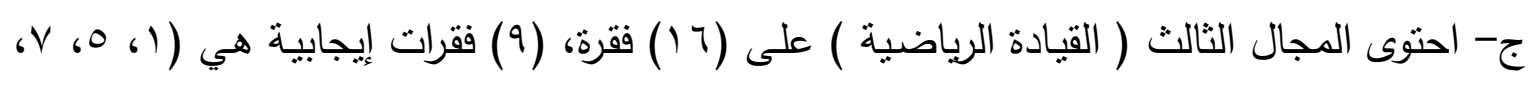

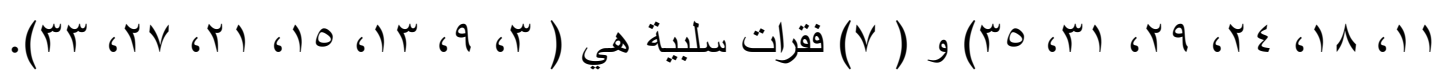

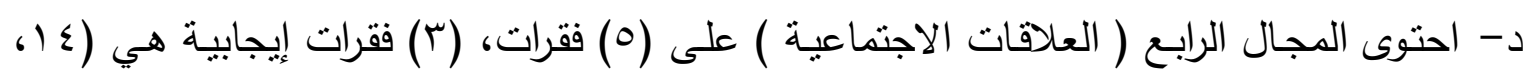

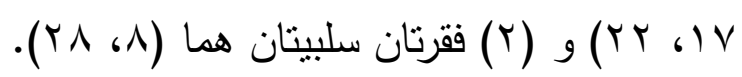

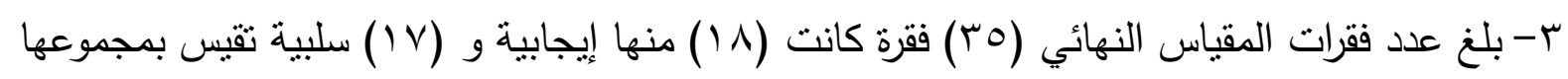
الرضا عن الدور القيادي لرؤساء الفرق في الألعاب الفرقية في العراق.

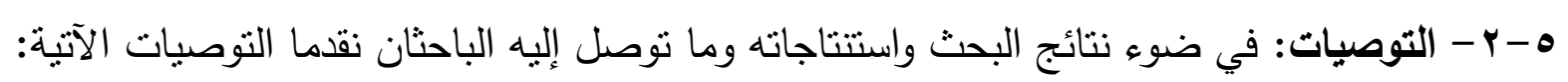

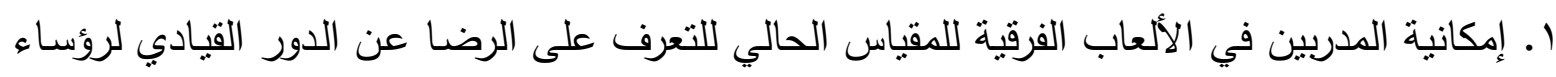

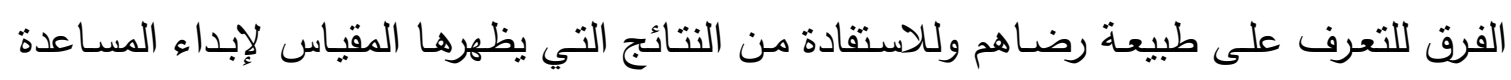

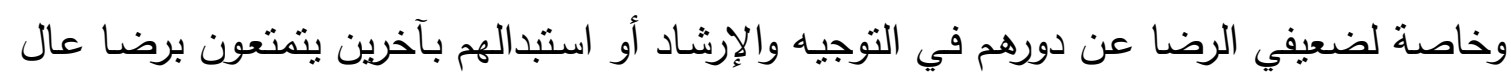
عن دورهم القيادي. r. إمكانية استخدام الددربين لمقياس (الرضا عن الدور القيادي لرؤساء الفرق ) من أجل النأكد من أن

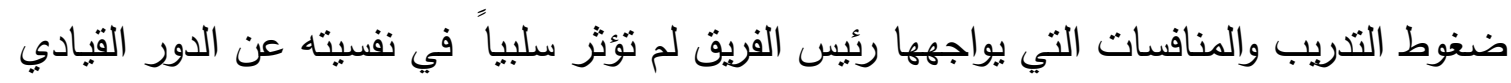
الذي يقوم به ويكون من (ץ-؟) مرات في الموسم الرياضي الواحد.

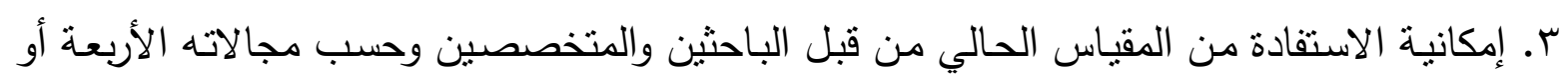

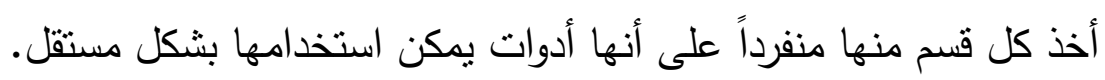


ـ. يمكن استخدام المقياس الحالي في دراسات تكثف عن العلاقة بين الرضا عن الدور القيادي لرؤساء

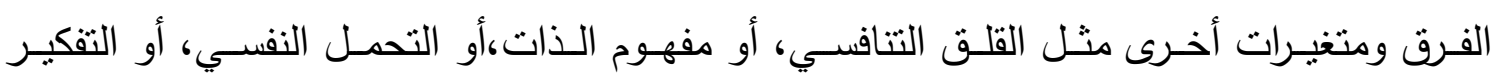
الإبداعي،أو دافعية الإنجاز،أو التوجيه الرياضي...ألخ ).

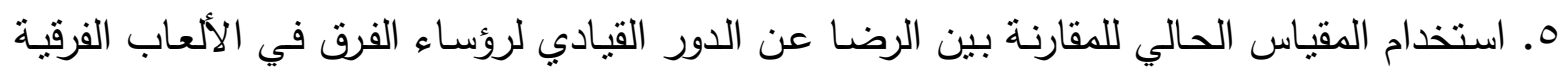
التي يمارسونها ( قدم، سلة، طائرة، يد ).

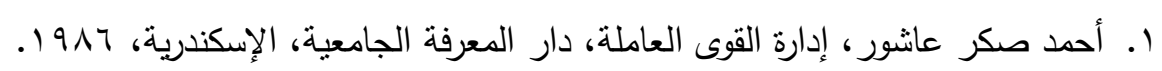

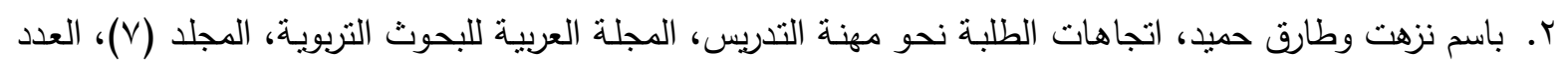
$.191 \mathrm{~V} ،(Y)$ r. بنيامين بلوم وآخرين، تقييم الطالب التجمعي والتكويني، ( ترجمة ) محمد أمين فقي وآخرين، مطابع المكتب المصري

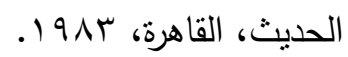

ع. حامد بدر، الرضـا الوظيفي لأعضـاء هيئة التدريس والعاملين لكليـة التجـارة والاقتصـاد والعلوم السياسية، جامعـة

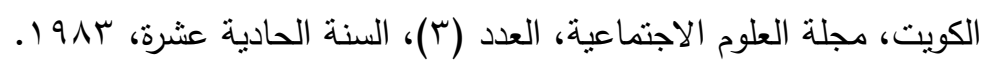

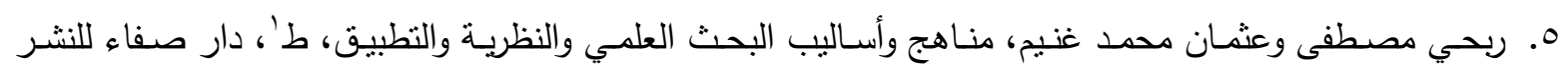

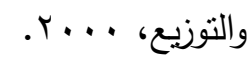

ج. ريـاض حسازم فتحي، أثنر برنـامج إرشـادي بأسـلوبين في تتميـة التوافق النفسي والاجتمـاعي لدى طـلاب المرحلـة

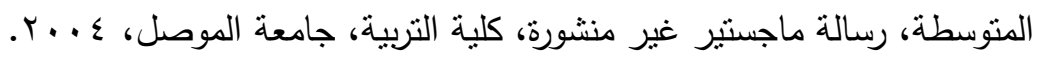

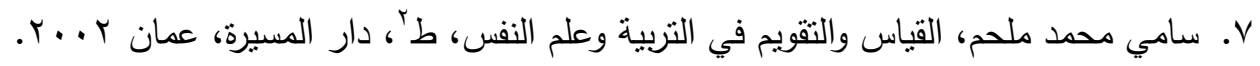

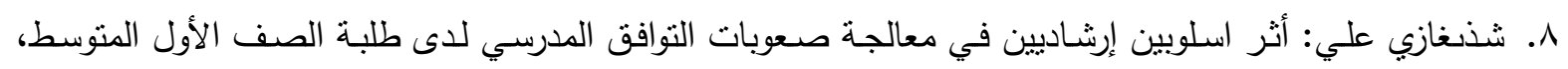

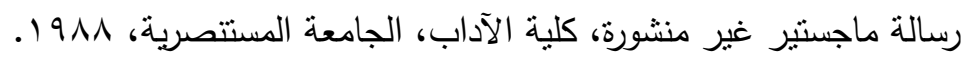

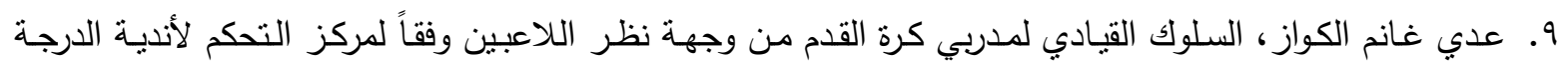

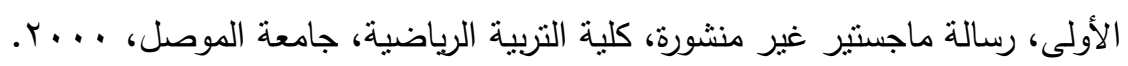

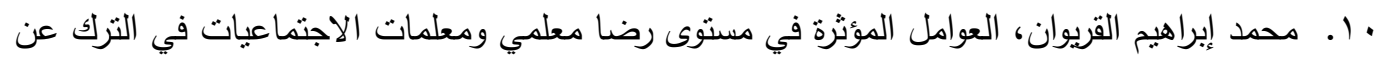

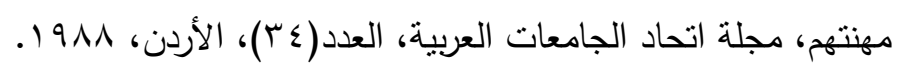
الـ فقي حمزة جاسم، السلوك القيادي وعلاقته بالرضا عن العمل لدى مدارس التربية الرياضية في محافظة الإدنة

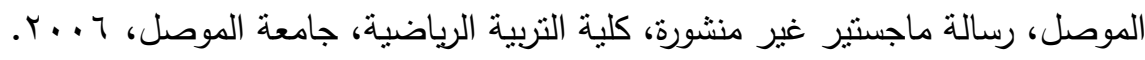

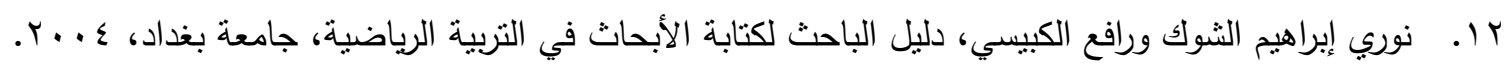

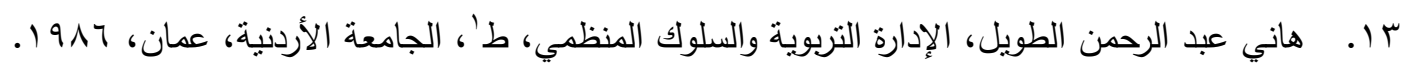

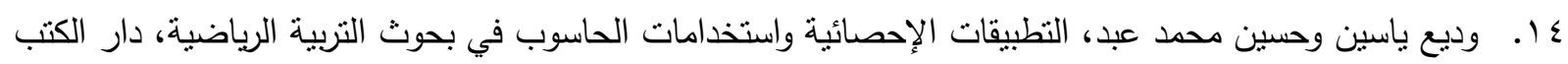

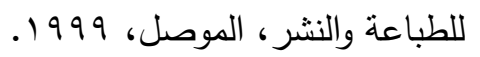

10 . وديع ياسين ونغم محمود، الرضا عن مهنته التربية الرياضية وعلاقته مستوى الطموح لدى مدربي الألعاب

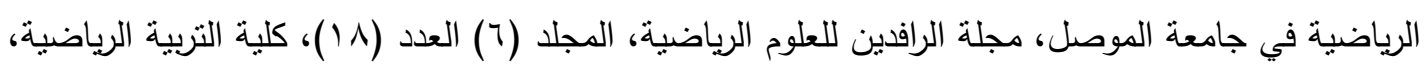

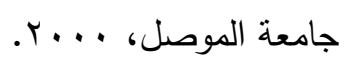


16. Balal, Bjr, an Occupational Study of Job Satisfaction Need Satisfaction, Journal of Exp Educational Vol. 32.No4.1964.

17.Davis, Keith, Human Behaviour and Work 5ed. Mc Grew Hill Company, New York, 1977.

18.Fergsson, George: Statistic Analysis in Psychology and Education, Mc, Grew Hill, New York, 1981.

ملحق (أ)

مقياس الرضا عن الدور القيادي لرؤساء الفرق في الألعاب الفرقية في العرلق إعداد ويناء الباحثان

أ.م.د. عكلة سليمان الحوري

م.م. سعدون عبد الرضا فرحان

\begin{tabular}{|c|c|c|c|c|c|}
\hline \multirow[t]{15}{*}{ نادراً } & \multirow[t]{2}{*}{ أحياناً } & \multirow[t]{2}{*}{ دائماً } & \multicolumn{2}{|r|}{ 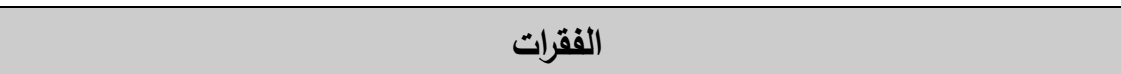 } & 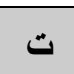 \\
\hline & & & & توفر لي قيادة الفريق فرصة لاكتساب الخبرات & 1 \\
\hline & & & & ا اشعر بالفخر لأني رئيس الفريق & $r$ \\
\hline & & & & بهيئ لي دوري فرصة الاعتماد على الآخرين & r \\
\hline & & & & إنني غير راضي عن أدائي بسبب تكليفي بمهمات خارج اختصاصي كلاعب & $\varepsilon$ \\
\hline & & & & أثنعر بتقدير الجمهور لي كوني رئيس الفريق & 0 \\
\hline & & & & تزداد ثقتي بنفسي عندما أقوم بواجبات رئيس الفريق & 7 \\
\hline & & & & تتسم واجباتي بالمسؤولية الدضافة لكوني لاعباً ورئيساً للفريق & V \\
\hline & & & & دوري القيادي لا يوسع علاقاني الاجتماعية & $\wedge$ \\
\hline & & & & رئاسة الفريق لا تتمي لي القدرة على حل المشكلات & 9 \\
\hline & & & & يكسبني دوري في تقدير واحترام الددري والإدارة & 1. \\
\hline & & & & يحقق لي دوري القيادي طموحي كلاعب & 11 \\
\hline & & & & لا أحب رئاسة الفريق لأنه عمل تطبيقي & ir \\
\hline & & & & لا أرغب بالاستمرار في قيادة الفريق & 1r \\
\hline & & & & أحس أن دوري ذو قيمة إنسانية & $1 \varepsilon$ \\
\hline نادراً & \multicolumn{2}{|c|}{ 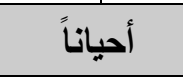 } & دائماً & 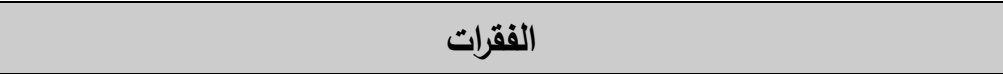 & ت \\
\hline & & & & لا أنتكن من اتخاذ قرارات خاصة برئاسة الفريق & 10 \\
\hline & & & & اكتثف نفسي بأداء دور رئيس الفريق & 17 \\
\hline & & & & يسرني ما أجده من تعاون من زملائي & IV \\
\hline
\end{tabular}




\begin{tabular}{|c|c|c|c|c|}
\hline & & & أحب دوري القيادي رغم ما يواجهني فيه من مشكلات & 11 \\
\hline & & & نجاحي في الأداء لا يمنحني تقديراً معنوياً & 19 \\
\hline & & & أتأثز بتهجم جمهور الخصم عليّ & r. \\
\hline & & & يقيئ لي دوري فرصة التخلص من المسئولية عند الإخفاق & r) \\
\hline & & & دوري القيادي يشعرني بالانتماء إلى الفريق & rt \\
\hline & & & أقبل على المباراة بكسل وتراخي & r \\
\hline & & & أنشعر بارتياح عند حضوري التدريب بانتظام & $r \varepsilon$ \\
\hline & & & لا يهتم المدرب بالمقترحات التي أطرحها & ro \\
\hline & & & أسعى إلى إنجاز دوري حتى لو كنت متعباً & rт \\
\hline & & & أرى أن كل لاعب قادر على أخذ دور رئاسة الفريق & rV \\
\hline & & & ارتفاع العائد المادي لي عن بقية اللاعبين يؤثر سلبياً على تقبل توجيهاتي & rᄉ \\
\hline & & & لدي إمكانية الششاركة في اتخاذ القرارات التي تخص الفريق & rq \\
\hline & & & رئاسة الفريق لا تميز شخصيتي عن اللاعبين & r. \\
\hline & & & أحس بتخويل مناسب من المدرب باتخاذ القرارات داخل الملعب & M \\
\hline & & & الخسارة المتكررة تقلل من اندفاعي نحو التدريب & rt \\
\hline & & & افقد سبطرتي على الفريق عندما نتأخر بالأهداف & r \\
\hline & & & أنثعر بالراحة عندما يلتزم اللاعبين توجيهاتي & $r \varepsilon$ \\
\hline & & & أقبل على رئاسة الفريق حتى عندما يكون الخصم من الفرق الجماهيرية & ro \\
\hline
\end{tabular}

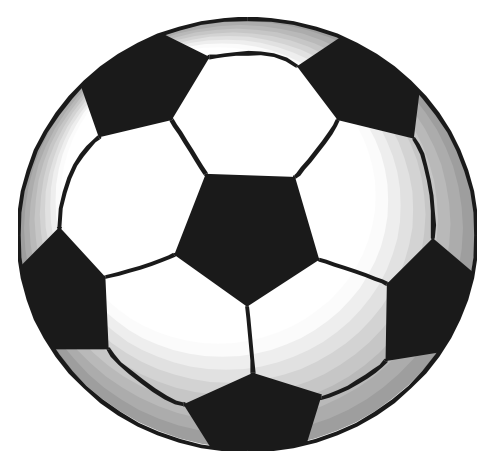

